\title{
LA COLMENA CIENTÍFICA O EL CAFÉ DE NEGRÍN: (RE)VISIÓN DE LA CIENCIA DE LA EDAD DE PLATA DESDE LA MEMORIA DEL TEATRO ESPAÑOL DEL SIGLO XXI
}

\author{
LA COLMENA CIENTÍFICA O EL CAFÉ DE NEGRÍN: \\ (RE)VIEW OF SCIENCE OF THE SILVER AGE \\ FROM THE MEMORY OF THE 21st CENTURY SPANISH THEATER
}

\begin{abstract}
María del Mar MAÑAS MARTÍNEZ
Universidad Complutense de Madrid. Instituto del Teatro de Madrid. mmarmmar@filol.ucm.es
\end{abstract}

Resumen: El presente trabajo se centra en La colmena científica o el café de Negrín (2010), de José Ramón Fernández, Premio Nacional de Literatura Dramática (2011), obra que se incluye en la tendencia de "teatro de la memoria". La obra reivindica el papel de la ciencia en La Edad de Plata, desarrollado gracias a la Junta de Ampliación de Estudios (JAE) y muestra cómo la guerra civil supuso el fin de todos esos ideales.

Palabras clave: José R. Fernández. La colmena científica o el café de Negrín. Ciencia. Edad de Plata. Teatro Español de la Memoria. S. XXI.

Abstract: The present essay focuses on La colmena cientifica o el café de Negrín (2010), by José Ramón Fernández, National Prize for Dramatic Literature (2011), a play that is included in the trend of "theater of memory". The play vindicates the role of science in the Silver Age, developed thanks 
to the Board of Extension of Studies (JAE) and shows how the civil war meant the end of all those ideals.

Key Words: Science. José R. Fernández. La colmena científica o el café de Negrin. Silver Age. Spanish Theatre of the Memory. S. XXI.

\section{SOBRE JOSÉ RAMÓN FERNÁNDEZ ${ }^{1}$}

José Ramón Fernández nació en Madrid en 1962. Es licenciado en Filología Hispánica por la UCM. Él dice que su generación "está sin bautizar" (Torres, 2011) pero pertenece a un grupo de dramaturgos que empieza a estrenar y publicar en la década de los 90 después de los que habían debutado con el Premio Bradomín surgido en 1984.

El Bradomín es un premio que no ha ganado José Ramón Fernández, en una trayectoria llena de galardones. Gana el Premio Calderón de la Barca en 1993 con Para quemar la memoria, obra que tiene su origen un taller vinculado al Centro Nacional de Nuevas Tendencias Escénicas impartido por Marco Antonio de la Parra². Según Rosa Serrano:

José Ramón Fernández pertenece a ese grupo de autores de la tercera promoción madrileña que asistieron a los últimos talleres organizados por el Centro Nacional de Nuevas Tendencias Escénicas (CNNTE), como fue el del chileno Marco Antonio de la Parra, durante los años 1992 y 1993. A dicho taller asistieron también, entre otros, Juan Mayorga, Raúl Hernández y Luis Miguel González, miembros del Teatro del Astillero, al cual ha pertenecido hasta hace unos años, el autor que motiva nuestro

${ }^{1}$ La mayoría de estos datos proceden de la biografía que aparece en el Cuaderno Pedagógico de El laberinto mágico, 92, editado por el CDN, p. 15. Disponible en línea: http:// cdn.mcu.es/wp-content/uploads/2012/08/N-92-El-laberinto-magico.pdf [21/04/2018]. ${ }^{2}$ Véase Fernández (2004). 
trabajo (Serrano, 2015: 42).

Es finalista en 1998 del Premio Tirso de Molina con La tierra; en 2003 recibe el Premio Lope de Vega por Nina y en 2011 el Premio Nacional de Literatura Dramática por La colmena cientifica o el café de Negrín. Otras obras suyas son Las mujeres fragantes (1997), Si amanece nos vamos (2001), El que fue mi hermano (Yakolev) (2004), Mi piedra Rosetta (2012) y J'attendrai (2014).

José Ramón Fernández ha participado en obras de autoría colectiva vinculadas al mencionado Teatro del Astillero formado en 1995. Es autor con Yolanda Pallín y Javier G. Yagüe de la Trilogía de la Juventud, un hito en la Sala Cuarta Pared, en la que se ofrece un retrato sociológico y sentimental de la juventud española a lo largo del siglo XX. Está compuesta por Las manos (1999), Imagina (2001) y 24/7 (2003). Las Manos ganó el Premio Max de la SGAE al mejor texto dramático en 2002 e Imagina fue finalista al Nacional de Literatura en 2003.

Entre sus obras escritas para proyectos conmemorativos como $\mathrm{La}$ colmena científica o el café de Negrín, se encuentran El libro infinito, para el tercer centenario de la Biblioteca Nacional en 2012 y Las Cervantas escrita en 2016 en colaboración con Inma Chacón también para un proyecto de la BNE.

Sus obras han sido traducidas a numerosos idiomas.

Ha impartido clases de dramaturgia en distintas escuelas, instituciones y talleres y ha realizado numerosas dramaturgias de obras ajenas de autores de muy distintos registros: Brecht/Weill, Arniches, Lorca, Shakespeare o Noel Coward. Ha sido Jefe de Prensa del Centro Dramático Nacional y en la actualidad trabaja en el Centro de Documentación Teatral del Ministerio de Educación, Cultura y Deporte. 


\section{CIRCUNSTANCIAS EN LAS QUE SE IMAGINÓ, SE ESCRIBIÓ Y SE ESTRENÓ LA COLMENA CIENTÍFICAO EL CAFÉ DE NEGRÍN}

La colmena científica o el café de Negrín (2010), de José Ramón Fernández es una obra teatral que surge como un encargo para conmemorar el centenario de la Residencia de Estudiantes ${ }^{4}$. Lejos de ser una obra de circunstancias, responde a las preocupaciones personales del autor, como demuestra Rosa Serrano en su tesis doctoral: Una escritura comprometida con su tiempo. El teatro de José Ramón Fernández (1992-2012)5.

Lo peculiar de la obra es que elige como objeto de recuerdo, la ciencia en España durante la Edad de Plata (1898-1936), época que por lo general se asocia al esplendor de las letras y las artes que han sido reivindicadas desde la ficción en los últimos tiempos. Esto hace interesante el estudio de La colmena científica o el café de Negrín.

José Ramón Fernández confirma lo insólito de que una obra que homenajee a la Residencia de Estudiantes tenga como objetivo "contar que

\footnotetext{
${ }^{3}$ Tomo el título prestado de los famosos prólogos que colocaba Enrique Jardiel Poncela a sus obras teatrales en las ediciones de Biblioteca Nueva.

${ }^{4}$ En la publicación aparece tras el título: "Obra escrita con motivo de los cien años de la Residencia de Estudiantes".

${ }^{5}$ En su tesis doctoral establece siete "Ejes de la escritura de José Ramón Fernández. Constantes y recurrentes" y luego los ejemplifica con el estudio de cinco de sus obras. Los ejes son:

1. Conocimiento del pasado y su relación con el presente. La memoria frente al olvido.

2. La importancia de la muerte en sus obras

3. Búsqueda de la propia identidad y relación con el otro.

4. El espacio como personaje (un personaje) principal (más). Los espacios determinan la historia

5. Exhaustividad documental. Importancia del lenguaje específico. Amor por el lenguaje 6 Intertextualidad avezada e intertextualidad cercana

7. Simbología/Evocación poética a través de las didascalias. Evolución a lo largo de estos veinte años de escritura.

Y las obras que estudia son: Para quemar la memoria, La tierra, Nina, La colmena científica o el café de Negrín, y Mi piedra Rosetta. El estudio sobre La colmena científica o el café de Negrín ocupa de la página 323 a la 402.
} 
la Residencia es mucho más que un lugar en el que coincidieron Lorca, Buñuel y Dalí” (Fernández, 2010b: 10), que sólo aparecen mencionados:

Se trataba de escribir una obra que sucediera en aquella tertulia que se formaba en el Laboratorio de Fisiología de la Residencia de Estudiantes de Madrid mientras el doctor Juan Negrín era su director. Era un modo, tal vez inesperado, de celebrar desde el teatro los primeros cien años de la Residencia, que habitualmente es recordada por tres iconos, tres genios artísticos únicos en el mundo, que compartieron alli días de juventud (Fernández, 2010c: 17 y 18).

Aunque la obra se conciba en el marco de la conmemoración del centenario de la Residencia en 2010, el Laboratorio de Fisiología no celebraría su centenario hasta 2016.

Actualmente contamos con importante bibliografía académica sobre la ciencia en España en la Edad de Plata ${ }^{6}$, pero ofreceremos unas breves pinceladas de contextualización histórica

La Junta para la Ampliación de Estudios e Investigaciones Científicas (JAE) ${ }^{7}$ presidida por Santiago Ramón y Cajal, heredera de los principios de la Institución Libre de Enseñanza sigue dos políticas para colocar a España en primera línea investigadora en el mundo. Una

\footnotetext{
${ }^{6}$ Véanse los numerosos trabajos de historia de la ciencia de Luis Enrique Otero Carvajal en su página personal https://www.ucm.es/oterocarvajal/historia-ciencia, y muy especialmente relacionado con esta obra, el estudio: "Juan Negrín y la Edad de Plata de la Ciencia en España" http://www.fundacionjuannegrin.com/weblog/2018/02/11/juannegrin-y-la-edad-de-plata-de-la-ciencia-en-espana/ [21/04/2018]. También hay estudios específicos sobre las mujeres en la ciencia española, véanse los de Carmen Magallón Portolés entre los que destaca: Pioneras españolas en las ciencias. Las mujeres del Instituto Nacional de Física y Química, Madrid: CSIC, 1998 y 2004, 2. ${ }^{a}$ ed. y el que aparece en las referencias bibliográficas (Magallón Portolés, 2007).

${ }^{7}$ Para las cuestiones referidas a la JAE, véase http://www.jae2010.csic.es/historia.php [21/04/2018].
} 
fue fomentar el contacto de los investigadores españoles con los de otros países y continentes para lo que fue fundamental la dotación de pensiones, equivalentes a las becas actuales, para que los investigadores, profesores y estudiantes fueran a estudiar y trabajar fuera. La otra medida fue la creación de una serie de centros, y laboratorios de investigación de disciplinas humanísticas y de disciplinas científicas y experimentales. Así en 1910, nacen el Centro de Estudios Históricos de Madrid, dirigido por Menéndez Pidal y el Laboratorio de Ciencias Físico-Naturales, dirigido por Ramón y Cajal, cuyo secretario fue Blas Cabrera, que aglutinó una serie de organismos científicos ya existentes y que se fue seccionando a partir de 1920. En 1910 se crea la Residencia de Estudiantes y en 1915 surge su versión femenina, la Residencia de Señoritas. Estas instituciones aparecen en La colmena cientifica o el café de Negrín.

Juan Negrín que acababa de regresar a España tras doctorarse en Medicina y haber estudiado en el Instituto de Fisiología de Leipzig, fue requerido por Cajal para dirigir el Laboratorio de Fisiología General en la Residencia de Estudiantes en 1916. La importancia de este laboratorio fue tal que estuvo a punto de que la JAE lo convirtiera en un Instituto de Fisiología, pero aunque no se consiguió, se potenciaron sus instalaciones.

La JAE promovió la incorporación de las mujeres a estos centros de Investigación luchando contra los prejuicios que dictaban que las carreras para una mujer eran magisterio, enfermería o farmacia.

En 1939, tras la Guerra Civil, todos los centros dependientes de la JAE tras su disolución pasaron a depender del recién creado Consejo Superior de Investigaciones Científicas. La ciencia avanzará con dificultad comparándola con su esplendor en la Edad de Plata ya que la mayoría de los científicos había optado por la República y fueron exiliados o depurados. Además, el que ocuparan los puestos científicos adeptos al régimen, complicó el que las mujeres accedieran a las ciencias experimentales porque el Franquismo presenta un modelo de mujer opuesto al de los años 20 y 30, retomando el papel de ángel del hogar.

En La colmena cientifica o el café de Negrín, por el Laboratorio de 
Fisiología, que según José Ramón Fernández es el primer personaje de la obra $^{8}$, transitan y conviven con ciertas licencias poéticas ${ }^{9}$, Negrín, Severo Ochoa y Ramón y Cajal, como representantes de distintas generaciones de la ciencia experimental en España, y representantes del mundo pedagógico que deriva de la Institución Libre de Enseñanza como Ángel Llorca, que vive en la Residencia, y Justa Freire. Trabajan ambos en el grupo Escolar Cervantes en Cuatro Caminos. El nexo entre el mundo científico y el mundo literario-artístico es José Moreno Villa, residente poeta, pintor y archivero en el Centro de Estudios Históricos que en su juventud había estudiado Química en Alemania. Moreno Villa es la voz que rememora el pasado desde su memoria. En el texto se alude a miembros de la generación del 27, especialmente en la escena tercera que transcurre en ese año, o a Valle Inclán, y también aparece Unamuno.

La colmena cientifica o el café de Negrín se estrena en Madrid, dirigida por Ernesto Caballero, en la Sala de la Princesa del Teatro María Guerrero el 13 de octubre de 2010 donde permanece hasta el 14 de noviembre de 2010. Es una producción del Centro Dramático Nacional y de la Residencia de Estudiantes ${ }^{10}$. El espectáculo estuvo en el XX Festival Don Quijote de teatro Hispánico, en París en noviembre del $2011^{11}$.

José Ramón Fernández escribe un artículo titulado "Donde haya maestros", en Primer Acto, en el que cuenta que para preparar la obra se sumergió "en uno de los capítulos más hermosos de la historia de mi

\footnotetext{
${ }^{8}$ Según estudia Rosa Serrano un eje temático de la producción de José Ramón Fernández que también aplica al estudio de La colmena cientifica o el café de Negrín es: "El espacio como personaje (un personaje) principal (más). Los espacios determinan la historia" (Serrano, 2015: 356-362).

${ }^{9}$ Señala el autor que Severo Ochoa y Ramón y Cajal, nuestros dos premios Nobel, no se llegaron a conocer.

${ }^{10} \mathrm{El}$ reparto fue el siguiente: José Moreno Villa (José Luis Esteban), Juan Negrín (David Luque), Justa Freire (Lola Manzano), Santiago Ramón y Cajal (Paco Ochoa), Severo Ochoa (Iñaki Rikarte), Ángel Llorca (Pedro Ocaña). El personaje de Miguel de Unamuno es interpretado por los actores (Pedro Ocaña, Iñaki Rikarte, Paco Ochoa y David Luque). El equipo artístico fue el siguiente: Escenografía (Curt Allen Wilmer), Iluminación (Juan Gómez-Cornejo),Vestuario (Patricia Hitos) y Videoescena (Álvaro Luna)

${ }^{11}$ http://paris.cervantes.es/FichasCultura/Ficha76822_30_1.htm [21/04/2018].
} 
país" (Fernández, 2013: 38). Alaba la pedagogía de la época promovida por la Institución Libre de Enseñanza y la importancia de la educación en la niñez, incluye algunos fragmentos de la obra sobre el tema y señala las muchas satisfacciones que le deparó la obra:

[...] Como el saludo del actor Santiago Ramos, al salir de la función, que resumía exactamente lo que yo había pretendido: "yo quiero ser un español de esa España", me dijo. Un país cuyas señas de identidad fuesen "el valor de la educación, la tolerancia y la cultura [...] (Fernández, 2013: 38).

El texto de La colmena cientifica o el café de Negrín presenta diferencias con respecto a su representación. Hay una grabación del espectáculo en el Centro de Documentación Teatral ${ }^{12}$, y sobre su puesta en escena se puede consultar también el Cuaderno Pedagógico publicado por el CDN.

José Ramón Fernández se hace eco de las diferencias en el "Prólogo del autor" a La colmena científica o el café de Negrín y habla de dos versiones:

Tantas historias... y la necesidad, sin embargo, de que la obra fuese corta, no más de setenta minutos. Decidimos que valía la pena el esfuerzo de escribir dos versiones: una para que se publicase en libro y otra que sirviese como punto de partida de los ensayos, en los que el director de escena es quien asume la responsabilidad de definir el texto de la representación [...] (Fernández, 2010c: 25).

En el Cuaderno Pedagógico vuelve a hablar de esas diferencias:

\footnotetext{
${ }^{12}$ La colmena cientifica o el café de Negrín. Filmación. Centro de Documentación Teatral. También hay en línea dos videos con dos fragmentos https://vimeo.com/17553598 y https://www.youtube.com/watch? $v=H i m g v b H n 9 g o$ [21/04/2018].
} 
En cuanto al texto resultante tenía una duración que, aunque estaba en la línea de una función al uso — por ejemplo, nuestra reciente versión de $\mathrm{El}$ avaro- era demasiado larga para la producción que se plantea, en la Sala de la Princesa. Decidimos que la Residencia de Estudiantes publicaría la versión larga en la que, además de los mencionados, aparecen madame Curie y Francisco Grande Covián-y que ajustaría una versión para que durase aproximadamente una hora (Fernández, 2010b: 11).

La Sala de la Princesa surge en 2003 en el espacio de la antigua cafetería del María Guerrero, debajo del teatro. Es la sala pequeña y en cierto modo alternativa y toma el nombre original del Teatro que no se llama María Guerrero hasta 1931. Tiene capacidad máxima para 120 butacas y puede ser modificada. Su tamaño la hace apropiada para obras intimistas con un decorado y montaje sencillo y funcional, lo que se aprecia bien en La colmena científica o el café de Negrín. Las obras deben durar alrededor de una hora porque cuando empiecen las funciones en la Sala María Guerrero, las de la Princesa tienen que haber acabado ${ }^{13}$ para que no haya interferencias de ruidos ni de público, permitiendo incluso que un mismo espectador pueda acudir a las dos salas el mismo día. Funciona igual la Sala Francisco Nieva del otro teatro del CDN, el Valle Inclán.

\section{EN "LA RESI", LA VIDA RIMA...}

Moreno Villa le dice a Negrín:

MORENO VILLA.- En los Altos del Hipódromo. Madrid era moderno. Se construían los edificios más modernos de Europa para coronar la Gran Vía, en la plaza del Callao. Y, gracias al empeño de

\footnotetext{
${ }^{13}$ Agradezco a Concha Largo, la Coordinadora de Actividades Pedagógicas del CDN, la explicación de esta exigencia.
} 
Cajal, Severo y tú os disteis la mano en el laboratorio de la Residencia. Un día de 1925, La vida rima, algunas veces (Fernández, 2010a: 59).

La frase "La vida rima, algunas veces" se suprime en la versión de la representación. De "rimas internas" vamos a hablar en un pequeño juego. Existe un espectáculo atípico llamado Batalla en la Residencia en el que aparecían los personajes habituales de la Residencia de Estudiantes. El título hace referencia a La batalla teatral de Luis Araquistáin que, primera rima, es el impulsor del documental ¿Qué es España $?^{14}$, que según reconoce José Ramón Fernández, ve para documentarse. Algunas de sus imágenes se proyectan en La colmena científica o el café de Negrín en una especie de pizarra electrónica que hace las veces de pizarra y de pantalla.

Hay un dossier sobre Batalla en la Residencia en la Revista Teatral ADE ${ }^{15}$. Batalla en la Residencia es una dramatización colectiva de

${ }^{14}$ La película ¿Qué es España? es un documental realizado por Luis Araquistáin y Cayetano Coll y Cuchí fechado en 1926, al que se le añadieron imágenes en 1929, sobre la educación, la investigación científica y la cultura en la España de los años 20, en el que aparecen imágenes de las personalidades más destacadas de la época en esos ámbitos. Se rodó para ilustrar las conferencias del político socialista Luis Araquistáin y del intelectual puertorriqueño Coll y Cuchí sobre las España Moderna en Mexico, Antillas y Centroamérica. Está dividido en 3 partes: "Precursores de la cultura contemporánea", "Investigación científica" y "Renovación del sistema educativo". También fue utilizada para las conferencias del político socialista Rodolfo Llopis en Latinoamérica en el año 30, y para ello eliminó unas partes y añadió otras, por eso las imágenes del grupo Escolar Cervantes, donde trabajaban Justa Freire y Ángel Llorca, aparecen fechadas en 1929. Ha sido objeto de una reconstrucción del IVAC auspiciada por la Sociedad Estatal de conmemoraciones y la Residencia del Estudiante.

Puede consultarse la página del IVAC de donde se ha extraído esta información:

http://www.restauracionesfilmoteca.com/cine-espanol/no-ficcion/que-es-espana/ [21/04/2018].

La película puede verse en la red en la siguiente dirección:

https://vimeo.com/83834466 [21/04/2018].

${ }^{15}$ Revista Teatral de la Asociación de Directores de Escena de España. ADE, n. ${ }^{\circ} 28$, enero (1993).Hay diversos artículos: "Sobre batalla en la Residencia" de las págs. 6 a 25 divididos en dos secciones, "Desde la platea", firmados por críticos teatrales y "Desde el escenario", firmados por los participantes en el montaje que no eran actores profesionales sino directores de escena y profesores universitarios. Eran: Juan Antonio Hormigón (Gar- 
textos de crítica teatral realizada por Juan Antonio Hormigón, Guillermo Heras, Fernando Doménech y Carlos Rodríguez, con dirección escénica de Hormigón y Heras, asistidos por Antonio López-Dávila Plata. Es una producción de la Asociación de Directores de Teatro de España que se representó del 27 al 29 de noviembre de 1993 en la Sala Olimpia, sede del CNNTE. En la obra asistimos a una velada en la Residencia de Estudiantes en 1935 en la que participan: Araquistáin, García Lorca, Machado, Azorín, Buñuel, Pérez de Ayala, Gómez de la Serna, Díez Canedo, Sender, Xirgu, Rivas Cherif, Azaña y Aub, entre otros. Los asistentes polemizan acerca del teatro exponiendo las ideas de sus escritos. Para continuar con la rima, y van dos, un joven Max Aub estaba interpretado por un joven Ernesto Caballero, director de La colmena cientifica o el café de Negrín.

José Ramón Fernández adaptó a Max Aub, tercera rima, en lo que en terminología de Sanchis Sinisterra podríamos llamar una "narraturgia" de El laberinto mágico, surgida de un taller dirigido por Ernesto Caballero, ya director del CDN, que luego pasaría a obra de exhibición comercial en el Teatro Valle Inclán en el 2016 dirigida por Ernesto Caballero, cuarta rima, que obtendría por ella el XI Premio Valle Inclán en 2017.

Y siguiendo con rarezas, hay una obra no nata de José Sanchis Sinisterra, de la que habla en ocasiones, situada en la Residencia de Estudiantes. Cuando en una entrevista le piden que defina la experiencia de la guerra civil, contesta:

SANCHIS SINISTERRA: [...] fue una tragedia. Una tragedia que partió en dos la historia de un país. Sobre todo teniendo en cuenta lo que estaba ocurriendo en España en los años anteriores, en la década anterior. Por eso ¡Ay, Carmela! y Terror

cía Lorca), Guillermo Heras (Gómez de la Serna), Antonio Joven (Rivas Cherif), María Ruiz (Margarita Xirgu), Jesús Cracio (Luis Araquistáin), Pedro Álvarez Osorio (Díaz Canedo), Ángel Fernández Montesinos (Ortega y Gasset), Jorge Eines (Luis Buñel),Antonio Malonda (Valle Inclán), Agustín Iglesias (Antonio Machado), Andrés Amorós (Pérez de Ayala), Juan Antonio Quintana (Azorín), Manuel Canseco (Unamuno), Juan Margallo (Azaña), Jorge Urrutia (Jiménez Fraud) y Ernesto Caballero (Max Aub). 
y miseria en el primer franquismo serían dos partes de otra trilogía: la trilogía de la guerra civil. La primera obra, que no está escrita, tiene que ver con ese periodo ${ }^{16}$ : el tránsito de la dictadura de Primo de Rivera a la Segunda República, cuando en España se produjo esa increíble floración de jóvenes poetas, artistas, intelectuales que se conoce como la Generación del 27: Lorca, Buñuel, Dalí y tantos otros, que irrumpieron en la vida cultural con la convicción de que ya éramos Europa, de que España entraba por fin en la modernidad, de que ya estaba en consonancia con los movimientos culturales y científicos del mundo. Y la obra (de la que imaginé hasta el título: Asesinato en la colina de los chopos) mostraría ese momento de entusiasmo, amenazado por el fantasma del fascismo, y hasta qué punto la guerra civil fue un golpe brutal, la pérdida de una posibilidad para España de ser un país normal (Sanchis Sinisterra, 2009: 303-304).

\section{LA MEMORIA EN LA COLMENA CIENTÍFICA O EL CAFÉ DE NEGRÍN Y ALGUNAS CUESTIONES SOBRE EL TEXTO Y LA REPRESENTACIÓN}

Wilfried Floeck en un trabajo de título revelador, "Del drama histórico al teatro de la memoria. Lucha contra el olvido y búsqueda de identidad en el teatro español reciente", explica cómo el teatro español en los primeros años de la democracia cambia su tratamiento de la historia reciente. Durante el franquismo sólo se podía ofrecer la versión oficial y

\footnotetext{
${ }^{16}$ Según cuenta Milagros Sanchez Arnosi en el prólogo de Terror y Miseria del primer franquismo, Sanchis comenzó a escribirla en 1984, pero la abandonó para dedicarse a la redacción de Ay Carmela: "Asesinato en la colina de los chopos, nombre con el que Juan Ramón Jiménez llamaba a la Residencia de Estudiantes, y que tendría como personajes a Dalí, Lorca, Buñuel, Pepín Bello, etc. y estaría ambientada durante la República. La trama se centraría en el asesinato de un residente no famoso, asesinato que se convertiría en la premonición de la barbarie del fascismo por venir" (Sánchez Arnosi, 2003: 30).
} 
en la transición se había impuesto un pacto de silencio.

Además podemos observar en las últimas décadas un creciente afán de conmemoración del pasado reciente, que está aumentando cada vez más en los últimos años. El modelo del drama histórico parece haber evolucionado hacia el modelo de un teatro de la memoria que lucha abiertamente contra el olvido de un pasado tabuizado durante mucho tiempo. También entre los dramaturgos de la democracia la noción de teatro de la memoria parecer preferirse frente al término tradicional de drama histórico [...] (Floeck, 2005: 186).

Y precisamente cita a Sanchis Sinisterra. Tras analizar cuatro obras representativas de esa tendencia (Las bicicletas son para el verano de Fernán Gómez (1982), El álbum familiar de Alonso de Santos (1982), ¡Ay Carmela! (1987) y Terror y miseria en el primera franquismo (2002) ambas de Sanchis Sinisterra), concluye:

A pesar de sus distintos matices ya las primeras obras analizadas aqui muestran rasgos temáticos y estéticos comunes que las distinguen del modelo del drama histórico de Buero Vallejo y que permiten hablar de un cambio paradigmático del drama histórico hacia el teatro de la memoria. Son los mismos rasgos que la crítica ha destacado en las nuevas novelas históricas, que se denominan también como novelas de la memoria. Estas características pueden resumirse en una tendencia a la despolitización, a la plasmación multiperspectivistica y a la subjetivación de la perspectiva, a la fragmentación, y a la estructura abierta, que exige la participación activa del lector o del espectador. El teatro de la memoria muestra su preocupación por el pasado nacional y la reconstrucción de una identidad colectiva, pero rechaza cualquier tipo de comprensión totalitarista de la historia y se 
dirige contra la visión maniqueista de la generación anterior [...] (Floeck, 2006: 205).

Según Rosa Serrano, "el modelo de teatralidad en que se inscribe José Ramón Fernández sería el que Xavier Puchades define como Teatro de la Memoria; que es el teatro que" (Serrano, 2015: 42):

Ejercería una estrategia de resistencia frente a tópicos posmodernos como la pérdida de las ideologías o el Fin de la Historia. Introduce en el teatro histórico español el interés por la Historia mundial, aunque sinolvidar la nacional. Surevitalización coincide, precisamente, con el inicio de las primeras "guerras mediáticas" como la del Golfo y la de Yugoslavia, pero también, con la intención de recuperar un periodo histórico acallado en los primeros años de la democracia española (la posguerra y la Guerra Civil). Su consolidación como modelo de teatralidad se produce a finales de los $90 y$, aún hoy, se desarrolla con cierta intensidad. Los medios de producción teatral en los que se mueve son el "público" y el "alternativo" (Serrano 2015: 43) ${ }^{17}$.

El concepto de "despolitización” de Floeck se explica porque según Eszter Katona, el "teatro de la memoria" es un teatro "comprometido socialmente" pero "[...] sin la pretensión de realizar una reconstrucción fiel y documentada de los hechos históricos" (Katona: 2017: 135).

Jerónimo López Mozo considera La colmena científica o el café de Negrín como "teatro documento" pero haciéndolo "con un criterio abierto que permite incluir, no sólo las obras que cumplen estrictamente con los requisitos del género ${ }^{18}$, sino también las que, bajos diversas formas se

\footnotetext{
${ }^{17}$ Según cita Rosa Serrano en nota al pie, la cita procede de la tesis doctoral de Xavier Puchades (2005), Renovación teatral en España entre 1984-1998. Desde la escritura dramática: puesta en escena y recepción crítica (cap 3, p. 400).

${ }^{18} \mathrm{Se}$ refiere a los puntos expuestos por Weiss en sus "Notas sobre el teatro documento" en 1968. César de Vicente resume las características del teatro-documento: "El teatro docu-
} 
aproximan a ellos" (López Mozo, 2017: 23), ya que opina que "documento y ficción son compatibles” (López Mozo, 2017: 24).

Según Rosa Serrano:

Como conclusión a este primer eje decir que el pasado en su relación con el presente y la memoria frente al olvido no sólo juegan un papel importante dentro de la obra, sino que La colmena científica o El café de Negrín supone en sí mismo el eje, puesto que la historia que se nos cuenta es real (Serrano, 2015, 329-339).

La acotación inicial de la obra nos advierte:

Esta historia evocada desde México en 1946 por José Moreno Villa sucede entre 1925 y 1936 en el Laboratorio de Fisiología ubicado en el Pabellón Transatlántico de la Residencia de Estudiantes de Madrid (Fernández, 2010a: 35).

“El Pabellón Transatlántico" es bautizado así por Moreno Villa, malagueño con nostalgia del mar "[...] por ese balcón de borda que tenemos arriba y porque sobre la azotea flotan nuestras ropas como equipos de tripulación [...]" (Fernández, 2010a: 62). Para Llorca es "colmena científica" y lo explica al final de la obra por la evocación del café, dejando así unidos los dos términos del título de la obra:

LLORCA.-Echo de menos los cafés. Por lo menos de eso no

mento, iniciado en 1917 en la URSS, fue teorizado y desarrollado en la práctica teatral por Erwin Piscator y Peter Weiss como una rama del teatro político. Entre sus características fundamentales están la renuncia a la fábula, la radical historicidad de su discurso, la articulación científica de sus elementos y su constitución como construcción dela realidad" (C. de Vicente, 2016: 34). Y llega a la conclusión de que "El teatro de la memoria es al teatro documento lo que el teatro social es al teatro político" (C. de Vicente, 2016: 43). Cf. al respecto también José Romera Castillo, ed. (2017). 
se le puede echar la culpa a esta guerra. Llevamos dos años sin tomar un café decente, desde que trasladaron su laboratorio a la nueva facultad de Medicina. También echo de menos esta sensación de colmena laboriosa. Recuerdo que pensé en esto como una colmena una tarde, hace años; ya saben que me daba un paseo después de comer por ahi detrás, por donde pastaban las vacas antes de aquel café estupendo que nos ofrecía. Desde ese montículo se les veía a ustedes trabajando, cada grupo en su laboratorio ${ }^{19}$ a través de los ventanales. En un extremo el de don Pio del Río, en otro el de Paulino Suárez y en medio el de Calandre y éste. Eran como abejas laboriosas en sus celdas. Si que lo echo de menos (Fernández, 2010a: 160-161).

"En este laboratorio el café es una cosa seria" (Fernández, 2010a: 51), le dice Negrín a Severo Ochoa nada más llegar, al que, para su sorpresa, pone a moler café. Y continúa Llorca:

LLORCA.- He soñado que todo esto se convertía en ceniza. Que caminaba por este lugar y que nadie había oído hablar de nosotros. Ni del trabajo de estos laboratorios ni de la Residencia. He soñado que nuestra vida no habia servido para nada ¿Y si no queda nada de todo esto? ¿Y si cierran la Residencia? ¿Y si cierran el Colegio Cervantes? ¿Y si queman todo lo que se ha hecho? ¿Y si nos matan? ¿Y si nos olvidan? No, no me mire así. No soy un derrotista. Fue una mala noche. Yo sé que no pueden. No pueden matarnos a todos, ni olvidarnos a

\footnotetext{
19“"La colmena científica" sería, pues, con propiedad, la suma de los distintos laboratorios que convivían en la Residencia de Estudiantes. Calandre era el director del laboratorio de Anatomía Microscópica fundado en 1914; Pío del Rio era el director el Laboratorio de Histopatología del Sistema Nervioso desde finales del año 20, al que intenta trasladarse Severo Ochoa al ver que Negrín desatiende el laboratorio por su ocupación política y Paulino Suárez dirigía el Laboratorio de Bacteriología desde 1921 y en 1932 sería nombrado Director Adjunto de la Residencia de Estudiantes. Véase http://www.residencia.csic.es/ jae/protagonistas/index.htm [21/04/2018].
} 
todos. Le he limpiado los mocos a demasiada gente para que no quede ni uno que nos quiera recordar. No me puedo imaginar una patria callada que ya no se acuerde de nosotros (Fernández, 2010a: 172-173).

A este sueño premonitorio se le podría aplicar el que "el sueño de la razón produce monstruos", porque la derrota de los vencidos en la Guerra Civil supuso en buena parte, el triunfo del "Muera la Inteligencia" de Millán Astray en el incidente de Salamanca con Unamuno. A Millán Astray, volvemos ahora, y de nuevo será una "cuestión de rima".

Moreno Villa responde a Llorca en el texto desde la evocación del futuro $^{20}$ :

MORENO VILLA.- Harán lo posible por borrar tu nombre. Te quitarán hasta el derecho a la jubilación. Volverás a Madrid y morirás en la miseria, la noche antes de mudarte a la casa de Justa. Justa acompañará tu cuerpo y guardará tus papeles. Y vivirá en España, en medio del silencio. Tú saldrás de Madrid en un tren con cien niños y volverás para morir en Madrid. Yo saldré con Machado y su madre, con Del Río, con Navarro Tomás y con Victorio Macho (Fernández, 2010a: 173).

Esos nombres, que la España oficial hizo lo posible por borrar, vuelven hoy, literalmente, a las calles de Madrid y así en los cambios del callejero por la Ley de Memoria Histórica, la "Calle del General Millán Astray" ha pasado a ser, en una suerte de justicia poética, "Calle de la Maestra Justa Freire", y la del "General Rodrigo", la del "Calle del Maestro Ángel Llorca".

Según Sanchis Sinisterra:

\footnotetext{
${ }^{20}$ En la representación lo hace cuando Llorca sale de escena, mientras va dando vueltas con la mano mecánicamente al asiento de un taburete, en una especie de trance:
} 
El tema esencial de ;Ay, Carmela! — por lo que se ha representado mucho en América Latina - es la segunda muerte de los muertos: el olvido. Carmela es una muerta, y luego van a ser más, que no quiere borrarse, que no quiere disgregarse o dejar de ser. Ella pretende estar ahí, como una mosca cojonera. Y nos recuerda una idea esencial: ojo, olvidar a los muertos es matarles por segunda vez (Sanchis Sinisterra, 2005).

Justa Freire, es la única mujer que aparece en La colmena cientifica o el café de Negrín. La elige su autor porque:

Yo quería que hubiese un personaje femenino en el que pudiéramos ver a la nueva mujer que buscaba su sitio en los años 20 de aquella España. Justa es maestra en un proyecto pedagógico de vanguardia y al tiempo es una mujer inquieta, uno de los quinientos socios de la Sociedad de Conferencias de la Residencia que trajeron a Madrid a Einstein, Le Corbusier, Howard Carter, H.G. Wells o Marie Curie en aquellos años (Fernández, 2010b: 13).

Justa se quedó en España tras la guerra en un exilio interior, como María Moliner y tras pasar por cárcel y depuración tardó mucho en recuperar una cierta "normalidad" en su carrera. Tuvo que impartir clase en la escuela privada y cuando pidió el reingreso de maestra pública después le fue prohibido ejercer en Madrid, cosa que consiguió a edad avanzada. Se demuestra la transcendencia de la obra que estudiamos cuando en la presentación de una biografía actual leemos: "Su retrato literario nos llegó a través de la obra de teatro La colmena científica o el café de Negrín, con la que José Ramón Fernández obtuvo el Premio Nacional de Literatura Dramática 2011"21.

\footnotetext{
${ }^{21}$ Véase la presentación del libro de María del Mar Pozo Andrés Justa Freire o la pasión de educar. Biografía de una maestra atrapada en la historia de España (1896-
} 
Unamuno pregunta a Justa si vive en la Residencia de Señoritas y ella dice que no, que tiene casa en Madrid:

UNAMUNO.- - Tengo prometido que voy a ir. Aunque no me guste nada eso de "señoritas". Si son estudiantes, son estudiantes, Ese nombre parece de internado de monjas ursulinas [...] (Fernández, 2010a: 136).

Es Justa Freire quien intenta reivindicar la visibilidad de las mujeres en la ciencia en esta conversación, a propósito del documental ¿Qué es España?

MORENO VILLA. - ¿Y usted qué cree que le va a faltar a la película? Me refiero a ¿Qué es España?, no a la de Buñuel: JUSTA FREIRE. - Las mujeres. Si hacen una película sobre cientificos va a ver usted qué pocas salen. Y no es justo, porque si hay algo que está pasando ahora es que estudian muchas más mujeres, que leen, que van a los sitios. Pero claro...

OCHOA. - Estará bien que hagan la misma película dentro de diez años. Porque ahora las chicas jóvenes que están metiéndose en laboratorios son cientos. Me han dicho que el proyecto de los Laboratorios Foster está muy bien.

JUSTA FREIRE. - Claro, se lo habrán contado en los dancing que hacen en la Residencia de Señoritas. Se están espabilando mucho, Severo. Pero si, que es verdad. Serán treinta chicas cada año. Puede parecer poca cosa, pero es algo importante: Yo conozco a algunas a Rosa Herrera, a María Luz Navarro [...] (Fernández, 2010a: 113-114).

1965) (2013), en la página web de la editorial (Octaedro): https://www.octaedro.com/ es/producto:Cos/1/otras-colecciones/testimonios/justa-freire-o-la-pasion-de-educar/210 [21/04/2018]. 
Los laboratorios Foster eran los laboratorios situados en la Residencia de Señoritas (Magallón, 2007) fundados por Mary Louise Foster. Rosa Herrera era la directora y María Luz Navarro su ayudante. Las prácticas que se realizaban en dichos laboratorios podían ser convalidadas en la Universidad Central ${ }^{22}$.

Volviendo ahora al papel de la memoria, hay que destacar el discurso final que Moreno Villa evoca desde su exilio:

MORENO VILLA. - Yo también volveré. Lo sueño cada día. Lo soñamos muchos que guardamos la llave de casa como un tesoro. Volveré a Madrid y nada de todo aquello habrá pasado [...] Tengo la llave de mi habitación en el bolsillo (Fernández, 2010a: 174-175) [La redonda es mía].

Los corchetes indican el discurso intercalado que tiene reminiscencias de Max Aub, reconocidas por José Ramón Fernández:

Tomé una idea, que me pareció muy bella, de un escrito de Max Aub, que hizo un discurso como si hubiera entrado en la Real Academia y en el país no había habido guerra civil. Alli estaban escuchándole García Lorca, Alberti... Ese juego me parecia muy interesante como evocación de un mundo que se perdió por una tragedia pero que habria que intentar recuperar, es decir, rescatar todo ese acervo que hemos ido perdiendo, nombres importantísimos de nuestra cultura que podrían ser un referente en todo momento. La idea es que todo esto era nuestra Historia, conviene que la recuperemos (Fernández, 2010b: 15).

\footnotetext{
${ }^{22}$ Escúchese el programa de RNE Documentos: "Pioneras de la Ciencia en España", un programa de Julia Murga, 23 /08/20 16. En http://www.rtve.es/alacarta/audios/documentos-rne/documentos-rne-pioneras-ciencia-espana-19-03-16/3529806/[21/04/2018].
} 
El detalle de guardar la llave es muy interesante porque era tradición entre los sefardíes expulsados de España, el conservar las llaves de sus casas esperando volver algún día y así esas llaves fueron pasando de generación en generación. Una persona de la cultura de Moreno Villa, archivero del Centro de Estudios Históricos, conocería esa tradición. Guardando la llave, se identifica así como exiliado del 39 con los judíos expulsados de España en el siglo XV. Pero es que, como recoge Antonina Rodrigo:

En las cartas a sus familiares pudimos descubrir que Margarita Xirgu estuvo como una Penélope de la nostalgia tejiendo y destejiendo el sueño de su regreso a España, y que, como una sefardí, conservó la llave de su casa durante los 33 años que duró su exilio (Rodrigo, 1989: 143) [la redonda es mía].

Hay un guiño intertextual en ese Moreno Villa que guarda la llave en el bolsillo. Guardo la llave es un espectáculo colectivo con dramaturgia de José Ramón Fernández y puesta en escena de Antonio López-Dávila Plata, propuesto por José Monleón en el Festival Madrid Sur de 1999 y publicado en 2005, a raíz de un taller de El Astillero Teatro en el que cada dramaturgo escribía un texto sobre la memoria y el papel del exilio del 39. El espectáculo toma el título del escrito por José Ramón Fernández que, como reconoce en el prólogo, recoge esa anécdota de Margarita Xirgu. Margarita, sin apellido, le dicta a su amiga Amelia, también sin apellido ${ }^{23}$ pero es Amelia de la Torre, una carta para su familia contándoles que va a volver pronto: “¡Ah! No necesitaré llamar al timbre. Si no habéis cambiado la cerradura, guardo la llave ¡Que sorpresa os voy a dar! [...]" (Fernández, 2005: 67). Tras un artículo que César González Ruano dirige al público, Amelia, cierra la obra: "No volvió, no volvió nunca. Guardó la llave hasta el último día de su vida, que fue veinte años después, un día de primavera de 1969” (Fernández, 2005:68). Es una brevísima obra próxima

\footnotetext{
${ }^{23}$ Sería interesante plantearse por qué unas aparecen sin apellido y el otro sí tiene.
} 
al teatro documento ya que José Ramón Fernández reproduce una carta de Margarita Xirgu y el artículo de González Ruano ${ }^{24}$.

La colmena científica o el café de Negrín presenta algunas acotaciones muy bellas y líricas, difíciles de plasmar en la representación. Una acotación preciosa de tintes valleinclainanos que además ofrece un panorama temporal simultáneo uniendo a diversas generaciones, la encontramos al final de la escena cuarta. Las imágenes que evoca pertenecen al documental ¿Qué es España?

La pobre tortuga entrega su corazón a la ciencia bajo la mirada atenta de los tres hombres. Don José fuma cigarrillos ingleses en su cuarto, junto a la ventana. Justa da clase a sus niños. Don Ángel atraviesa el patio del colegio repartiendo coscorrones. El fantasma de Don Benito Pérez Galdós acaricia a su perro y pesa en el aire de España la ausencia de Unamuno (Fernández, 2010a: 122-123).

O abriendo la escena tercera hay otra acotación muy sutil para sugerir el posible enamoramiento de Justa Freire por Moreno Villa que también se deja ver en la representación porque ella lo escucha extasiada y en algún momento le coloca la pajarita: "Puede que los ojos de Justa se hayan quedado prendidos de la nuca de José, que no sabe; porque eso pasa a veces y no se llega a enterar nadie, nunca" (Fernández, 2010a: 71).

La estructura fragmentaria de la obra en seis escenas, permite cambiar o eliminar cosas. Así desaparece Marie Curie y las conversaciones que mantiene en el texto con Unamuno, Negrín y Justa Freire; aquellas en las que hablaba sobre la educación y las que refería José Ramón Fernández

${ }^{24 “ ¡ Y a ~ s e ~ s a l v o ́ ~ e l ~ t e a t r o ! ", ~ A r r i b a, ~} 26$ de agosto de 1949. Se publicó también en La Vanguardia Española. http://margaritaxirgu.es/castellano/vivencia/22vuelta/regreso. htm [21/04/2018]. Tradicionalmente se cree que la actriz desistió de su regreso por ese artículo. 
en "Donde haya maestros"25. Grande Covián, también desaparece, aunque algunas de sus frases las incorpora Severo Ochoa. Sí se le menciona en la representación para mantener la importancia del papel de la memoria, en la escena tercera, que se desarrolla en 1927. Moreno Villa le dice a Justa Freire: "Creo que no conoce a Francisco Grande Covián", se lo presenta y se produce una escena simpática en la que hablan de zarzuela porque Grande Covián y Severo Ochoa son asiduos a ese espectáculo. Tras esa conversación dice Moreno Villa, rememorando desde el futuro:

MORENO VILLA.- Tú no eres Paco Grande. Ya he olvidado tu cara, Te mezclo con Negrín y con tus compañeros. Recordar es hacer que las cosas vuelvan al corazón ${ }^{26}$ y si no vuelven es porque el corazón ya se ha hecho piedra. Por eso nos inventamos los recuerdos, para librarnos del miedo de quedarnos solos. Necesito que tú seas Paco Grande. Eres Paco Grande y eres Méndez, que no paraba de reír de hacernos reír. Eres Barreda y Sopeña y Valdecasas, y Puche y del Corral y Hernández Guerra. Es igual. Todos erais el mismo. Todos erais la Residencia, la Juventud eterna. La mejor juventud. Era primavera, casi verano. Era 1927 (Fernández, 2010a: 74-75).

Podemos pensar que si ha olvidado la cara de Paco Grande, este no tiene por qué aparecer. En la puesta en escena presenta a Justa a Paco Grande para inmediatamente corregirse: "Tú no eres Paco Grande..." manteniendo todo ese discurso.

En la representación, Ramón y Cajal, ni lleva barba, ni se parece a Ramón y Cajal. Señala Ernesto Caballero:

\footnotetext{
${ }^{25}$ Y así lo señala: “[...] no se rompan la cabeza los que vieron la obra, esto se modificó para la puesta en escena y sólo aparece como lo estoy contando aquí en el libro editado por la Residencia de Estudiantes" (Fernández, 2013: 36).

${ }^{26}$ Interesante reflexión sobre el sentido de las palabras basado en su etimología.
} 
Contamos con una base muy documentada, el trabajo del autor ha sido muy sesudo, exhaustivo en los detalles verídicos. Sobre esa base hemos querido hacer algo autónomo porque la ficción requiere abandonar un poco la documentación; si no se termina haciendo una conferencia ilustrada con actores disfrazados y eso es lo que hemos querido evitar. (Caballero, 2010: 25).

Aparece en la acotación: "Cajal, entrando desde otro lugar, plegando el tiempo" (Fernández, 2010a: 55) y en la representación vuelve a aparecer mientras se proyecta su imagen extraída de ¿Qué es España? en la pizarra-pantalla filmando la imagen él mismo, dándole a la manivela de un molinillo de café como si fuera la de una cámara. Es una solución interesante porque el molinillo se utiliza en la obra habitualmente y del mismo modo que Negrín pone a Grande Covián a moler Café, cuando Cajal le pide un café a Negrín y este le dice que no está molido, Cajal responde: "Lo tendré que hacer yo todo (Llena el molinillo y se pone a moler tranquilamente) [...]" (Fernández, 2010a: 116).

La representación de Unamuno es curiosa; desdoblado en cuatro de los actores de la obra, que aparecen a la vez, vestidos igual llevando una boina, y ocupando las cuatro esquinas del escenario y, en algunas ocasiones repitiendo a la vez la misma frase, mientras que en otras se turnan. Se le da así un carácter abrumador ${ }^{27}$ a Unamuno, del que Moreno Villa le explica a Justa Freire antes de su aparición que habla tanto que no deja hablar a los demás y que a veces se elige a un residente para que se quede de interlocutor permanente mientras que los demás entran y salen.

En la obra, las transiciones entre escenas son menos oníricas que en las acotaciones. No aparecen todas las indicaciones temporales

\footnotetext{
${ }^{27}$ Con respecto a si se ha tomado licencias históricas, contesta José Ramón Fernández: "Lo que evito es que ninguno de los personajes diga o haga algo contrario a lo que está documentado. Esto ha sido difícil con Unamuno, porque era un hombre muy contradictorio; podía defender una cosa y unos años después la contraria con la misma vehemencia. Me gustó mucho encontrar una frase de él que definía su actitud y es que si un hombre no se contradice es porque nunca ha dicho nada" (Fernández, 2010b: 14).
} 
de las escenas: 1925, 1927, 1929. Sólo aparece 1931, proyectada en la pizarra-pantalla porque es importante con la llegada de la República y 1936 porque es importante con la llegada de la guerra; es la destrucción del sueño y por eso la pizarra-pantalla aparece como un cristal roto. El suelo que está formado por baldosas hidráulicas hexagonales para dar la impresión de colmena, también se rompe en 1936, semejando el dibujo de unas neuronas, además. ${ }^{28}$

Antes hemos mencionado la escena, desaparecida en la representación al no aparecer Grande Covián, en la que hablan sobre zarzuela como algo simpático, porque es una especie de diálogo sainetero:

JUSTA FREIRE.- Asi que son ustedes ricos. Como van a la Zarzuela...

GRANDE COVIÁN.- No, en absoluto. Somos habitantes de los barrios altos. Una butaca de entresuelo son quince pesetas. Una de principal son diez y una de anfiteatro segundo son cinco. Depende de lo que vayamos a ver, nos sacrificamos más o menos. OCHOA.-En eso decide Paco, que lo sabe todo.

GRANDE COVIAN. - Este año nos esforzamos en enero, porque la ocasión era especial: El Barbero de Sevilla, pero tal como lo compuso Rosinni, con una mezzo soprano en lugar de una soprano ligera. Lo hizo Conchita Supervía sin filigranas, comme il faut. Pero a la ópera vamos poco. Vamos más a los conciertos de la sinfónica del Maestro Arbós, los domingos por la mañana en el Monumental Cinema. Es que a este sacarle es difícil. No sé si saben ustedes que cuando cierra el laboratorio se va estudiar alemán (Fernández, 2010a: 73-74).

Es digno de los juegos de palabras del género chico: son habitantes de los barrios altos, porque las localidades altas son las más baratas. Se

\footnotetext{
${ }^{28}$ Hay un apartado dedicado a "La escenografía de Curt Allen Wilmer" en el Cuaderno pedagógico, 49. Véase Wilmer (2010).
} 
divierten como el resto de los madrileños castizos, son más de zarzuela que de ópera, salvo excepciones. Lo de El Barbero de Sevilla no es baladí, porque justo antes de este diálogo oímos entrar cantando a Grande Covián y a Severo Ochoa "¡Che invenzione prelibata!” que es un dúo de esa ópera y Moreno Villa le tiene que explicar a Justa que es tradición que "cuando alguno de ellos encuentra algo que parece que funciona, suelta ‘Che invenzione prelibata!'”29 (Fernández, 2010a: 72-73). Es una visión deliciosa de los científicos, jóvenes, juguetones y un poco surrealistas. Si los habitantes más conocidos de la Residencia, Lorca, Dalí y Buñuel inventaban anaglifos, ¿por qué no van a poder cantar los científicos “ $¡$ Che invenzione prelibata!" a modo de su particular eureka cuando venga al caso? Al comienzo y al final suenan canciones americanas de la época por la radio, y las cantan y las bailan ${ }^{30}$. Y como manifestación de la época dice Justa: “A mí el cine me chala” (Fernández, 2010a: 83) imitando el lenguaje de sus niños del comedor y Llorca reflexiona sobre el origen gitano del término y sobre que "todos usamos el participio. Chalado" (Fernández, 2010a: 83). Señala Rosa Serrano ${ }^{31}$ el interés el interés de J.R Fernández por recuperar y explicar el origen de algunas palabras,

Y si la música es juguetona, la música también es melancólica. En la representación Moreno Villa le pregunta a Justa si le gusta la zarzuela y ella responde: “¿A mí? Me encanta”. En el texto no hay respuesta, “¿A mí?” (Fernández, 2010a: 67) es la última frase de la escena segunda, y la escena tercera se abre con ella canturreando "bajito, sin alardes ... 'tirano amor..." que es la romanza de la Duquesa de Jugar con fuego de Asenjo Barbieri y Ventura de la Vega ${ }^{32}$. Eso le sirve a Moreno Villa para hacer una

\footnotetext{
${ }^{29}$ Puede traducirse como "¡Qué idea tan deliciosa!".

${ }^{30}$ Es interesante el análisis de la intertextualidad de estas canciones que hace Rosa Serrano (2015: 371-373).

${ }^{31}$ Uno de los apartados de su tesis es: "Exhaustividad documental. Importancia del lenguaje específico. Amor por el lenguaje".

${ }^{32}$ En la representación, justo antes de que le pregunte Moreno Villa si le gusta la zarzuela, y estamos en 1925, aguzando el oído oímos a Justa tararear, y esto no está en el texto, "No puede ser" de La tabernera del puerto, de Sorozábal, Romero y Fernández Shaw, que no se estrena hasta 1936. En efecto, "no puede ser".
} 
evocación sobre el amor: "Tirano amor. Amé desastrosamente en aquellos años, Jacinta la pelirroja..." (Fernández, 2010a: 72).

Al desaparecer Grande Covián, Severo Ochoa asume alguna de sus frases. Grande Covián aunque sale poco, aporta a Ochoa la posibilidad de un amigo de su edad, otro científico brillante con el que incluso se divierte. En la representación nada nos distrae de su relación con Juan Negrín al que considera como su Padre. Así lo dice en la escena sexta: "Me vendió. Me engañó como a un niño [...] Para mí era como un Padre" (Fernández, 2010a: 163) cuando Negrín le había convencido para que se presentara a las oposiciones pero aprueba a otro candidato por razones políticas. En la acotación de la primera escena cuando se conocen, "Severo le da la mano como si se la diera a Dios Padre" (Fernández, 2010a: 50). Severo Ochoa se va decepcionando cuando Negrín va abandonando el laboratorio arrastrado por sus nuevas ocupaciones. Ochoa, al igual que Cajal, no es partidario de que los científicos se dediquen a la política:

CAJAL.- Entonces piensa usted repartir su tiempo entre la fisiología y las aventuras con su automóvil. Sí, si me entero de todo. Siempre hay alguien dispuesto a contar chismes. Y de usted se cuentan tales cosas que se diría que hablan del primo listo de Casanova. De las personas que me interesan me entero de todo. NEGRIN.- Creo que me puedo dedicar a la ciencia y a la política de forma simultánea.

CAJAL.—La gente normal no puede, desde luego. Ahora, que de usted se puede esperar uno cualquier cosa [...] (Fernández, 2010a: 121-122).

Y es que en la obra se transmite una imagen de Negrín como un ser excesivo, hiperactivo, casi un superhombre. Había en la época una leyenda ${ }^{33}$ propagada por sus enemigos que lo consideraba excesivo en todo, en la comida, en la bebida, en el sexo; de ahí lo de los comentarios

\footnotetext{
${ }^{33}$ Véase, por ejemplo el artículo de Stanley G. Payne (2009).
} 
de Cajal. Utilizaba el coche oficial y el laboratorio para esconder a los amigos que eran perseguidos políticamente, como Largo Caballero, pero es interesante reparar también en la expresión "el primo listo de Casanova" (Fernández, 2010a: 122).

Cuando al final de la segunda escena, Negrín se va porque ha quedado con su amigo Indalecio Prieto: "Intercambiamos información: yo le hablo de restaurantes y él me habla de zarzuela. Una reunión de expertos (Sale)" (Fernández, 2010a: 66), Moreno Villa dice:

MORENO VILLA. - No se llame a engaño, Ochoa. Al doctor Negrín le da tiempo para hacer de todo, pero al resto de los mortales, no. Él se va a hablar de zarzuela con su amigo Prieto, de zarzuela y de algo más, supongo; y luego se irá a cenar con alguien y después se irá con su familia, y dará clases y dirigirá esto. Y no se cansará nunca. (Entra un balón). Y si le diera por el balompié, agotaría a todos esos. Aqui en la Residencia hay dos equipos de balompié. Ande, salga a verlos correr y dar patadas y a que le dé el aire. Porque a partir de mañana no vuelve usted a ver la luz del día (Le da el balón) (Fernández, 2010a: 66-67).

Los días para Negrín parecen tener más horas que para el resto de los mortales, pero al final, las horas ya no son suficientes, y eso que sólo es ministro de hacienda. Se lamenta de que se quedó huérfano de Cajal y que ahora se va a quedar huérfano de amigos hasta que termine esto ("esto" es la guerra). Cuando Llorca le dice que "esto terminará pronto" y "volverá usted a lo suyo", responde:

NEGRÍN. - ¿Y qué es lo mío, Don Ángel? Mi pasión era este laboratorio. Lo que quería hacer con mi vida era esto. Trabajar con otros, formar un grupo de investigadores que viviese esto como una fiesta. Aquí tenía todo lo necesario para ser feliz: microscopios, cápsulas de Marey, reactivos, un polímetro, ranas 
en abundancia, una buena centrifuga, un colorimetro, una bomba de vacio... (Le ahoga la emoción; tiene que dejar de hablar para serenarse. Está describiendo un paraíso perdido) Y entusiasmo, El entusiasmo de Ochoa, de Valdecasas, de Covián, de Méndez, de Barreda....Está claro que nadie me va a recordar por mis estudios sobre "El papel de los adrenes en las glucosorias de origen bulbar". Llevo... no sé cuántos años llevo haciendo lo que tengo que hacer. Aunque esa faena no deja mucha huella, seguramente, ninguna.

MORENO VILLA. - Metafisico estáis

NEGRÍN._- Es que no duermo ¿Lo ven? Esto es lo que me pasa cuando paro. Que me da por pensar más de la cuenta. Estoy muy cansado.

MORENO VILLA.-ESo sí que es una noticia.

NEGRÍN.-Pero se me pasa con un café [...] mejor con dos [...] Les dejo [...] (Fernández, 2010a: 170).

Hay algo, de "ponerse estupendo" en Negrín bebiéndose de un trago los dos cafés para seguir manteniendo su personaje tras un momento de debilidad. Le frustra no poder conseguir que Ochoa se quede en España, como Cajal consiguió que se quedara él. Cajal le pasó el testigo a él y él se lo pasó a Severo Ochoa. Severo Ochoa se lo pasará en Estados Unidos, a otros, entre ellos mujeres, como Margarita Salas ${ }^{34}$.

Es muy interesante la despedida entre Ochoa y Negrín cuando accede a ayudarle para que se marche con el Dr. Meyerhof, a regañadientes, ya que en Alemania asciende el peligro del nazismo. Hay algo de fracaso, de traición. Piensa que se quiere pasar al otro bando, y Severo Ochoa le repite: "No quiero pasar al otro bando" (Fernández, 2010a: 169).

Unos segundos de silencio. Ochoa la ofrece la mano. Negrín se la estrecha.

\footnotetext{
${ }^{34}$ Remito de nuevo al programa Documentos de RNE de la nota 22.
} 
NEGRÍN.- Prométame una cosa, Ochoa. Si no nos matan, la próxima vez que nos veamos me dará usted un abrazo (Fernández, 2010a: 169).

Por eso en una de las acotaciones finales leemos: "El ruido de la metralla se funde con la música americana del principio, el abrazo al fondo de Negrín y Ochoa y la evocación de Moreno Villa" (Fernández, 2010a: 173).

En esa acotación vemos de nuevo esa fusión de tiempos, como si todo fuera posible, incluso lo que nunca pasó, y aquí no hubiera pasado nada.

\section{A MODO DE CONCLUSIÓN}

La colmena científica o el café de Negrín, de José Ramón Fernández es un texto que surge por encargo para conmemorar el centenario de la Residencia de Estudiantes y él convierte la conmemoración en una obra personal e inesperada, centrada en la labor del laboratorio de Negrín situado en la Residencia y que reivindica el valor de la ciencia en la Edad de Plata como uno más de los valores que son condenados al ostracismo tras el fin de la Guerra Civil. Construye una pieza de teatro de la memoria valiéndose de una sólida documentación pero sin hacer del teatro un documento. José Ramón Fernández (re) crea con un hondo sentido lírico desde la memoria de José Moreno Villa, como personaje, todo aquel pasado en el que los valores de la Institución Libre de Enseñanza y de la JAE consideraban que la educación, la ciencia y la cultura constituían las señas de identidad de un país. Construyendo un discurso radicalmente distinto al discurso oficial que se había dado después de la Guerra Civil, intenta suturar la brecha temporal que supuso la guerra con sus consecuencias enlazando el presente con el pasado como si nada de eso hubiera pasado. 


\section{REFERENCIAS BIBLIOGRÁFICAS}

CABALlERO, E. (2010). "Entrevista con el director, Ernesto Caballero". Cuaderno Pedagógico 49, 24-27. Disponible en línea: http:// cdn.mcu.es/wp-content/uploads/2012/08/49-LA-COLMENACIENTIFICA-O-EL-CAFE-DE-NEGRIN-10-11.pdf [30-04-2018].

FERNÁNDEZ, J. R. (2004). "Para quemar la memoria, un texto afortunado". Revista STICHOMYTHIA 2, s. p. Disponible en línea: http://parnaseo.uv.es/Ars/ESTICOMITIA/numero2/estudios/pres. pdf [21/04/2018]

(2005). "Guardo la llave". En Guardo la llave, AA.VV. Taller de Escritura Madrid-Sur, 65-68. Madrid: Teatro del Astillero, 16, con la colaboración del INAEM.

(2010a). La colmena científica o el café de Negrín. Madrid: Publicaciones de la Residencia de Estudiantes.

(2010b). "Entrevista con el autor, José Ramón Fernández". Cuaderno Pedagógico 49, 9-16. Disponible en línea: http://cdn.mcu.es/wpcontent/uploads/2012/08/49-LA-COLMENA-CIENTIFICA-O-ELCAFE-DE-NEGRIN-10-11.pdf [30/04/2018].

(2010c). "Prólogo del autor". En La colmena científica o el café de Negrín, 17-27. Madrid: Publicaciones de la Residencia de Estudiantes.

(2013). "Donde haya maestros". Primer Acto. Cuadernos de Investigación Teatral 345, II, 36-40.

FLOECK, W. (2006). "Del drama histórico al teatro de la memoria. Lucha contra el olvido y búsqueda de identidad en el teatro español reciente”. En Tendencias escénicas al inicio del siglo XXI, J. Romera Castillo (ed.), 185-209. Madrid: Visor Libros.

KATONA, E. (2017). "El teatro de la memoria: cinco dramas contra el olvido". Beoiberística, Revista de Estudios Ibéricos, Latinoamericanos y Comparativos I.1, 133-146 (también en http:// beoiberistica.fil.bg.ac.rs/index.php/beoiberistica/article/view/10 
[30/04/2018]).

LÓPEZ MOZO, J. (2017). "Mapa del teatro documento en los albores del siglo XXI en España”. En El teatro como documento artístico, histórico y cultural en los inicios del siglo XXI, J. Romera Castillo (ed.), 23-41. Madrid: Verbum.

MAGALLÓN PORTOLES, C. (2007). "El Laboratorio Foster de la Residencia de Señoritas. Las relaciones de la JAE con el International Institute for Girls in Spain, y la formación de las jóvenes investigadoras españolas". Asclepio. Revista de Historia de la Medicina y de la Ciencia LIX.2, julio-diciembre, 37-62 (también en: http://asclepio.revistas.csic.es/index.php/asclepio/ article/viewFile/231/227 [30/04/2018]).

OTERO CARVAJAL, L.E. (2018). “Juan Negrín y la edad de plata de la ciencia en España”. Fundación Juan Negrín. Disponible en línea: http://www.fundacionjuannegrin.com/weblog/2018/02/11/juannegrin-y-la-edad-de-plata-de-la-ciencia-en-espana/ [30/04/2018].

PAYNE, S. G. (2009). "El problema Negrín”. Revista de Libros 151-152 (julio-agosto), s. p. En https://www.revistadelibros.com/articulo_ imprimible.php? art $=4388 \& t=$ articulos $[21 / 04 / 2018]$

RODRIGO, A. (1989). "Margarita Xirgu en el exilio". Cuadernos hispanoamericanos 473-474, 143-158 (también en http:// bibliotecadigital.aecid.es/bibliodig/es/catalogo_imagenes/ imagen.cmd path $=1005775 \&$ posicion $=33 \&$ registrardownload $=1$ [10/07/2018]).

ROMERACASTILLO, J. (ed.) (2017). El teatro como documento artístico, histórico y cultural en los inicios del siglo XXI. Madrid: Verbum.

SANCHIS SINISTERRA, J. (2003). Terror y miseria en el primer franquismo. Milagros Sánchez Arnosi (ed.). Madrid: Cátedra. (2005). (Entrevista a) / realizada por J. A Ríos Carratalá. Disponible en línea: http://www.cervantesvirtual.com/obra/entrevista-a-josesanchis-sinisterra-11112005--0/ [30/04/2018]. (2009). (Entrevista a) / realizada por E. Amorim Vieira y S. Rojo. 
Aletria, Revista de Estudos de Literatura 2.19, jan-jun., 297-307 (también en: http://www.periodicos.letras.ufmg.br/index.php/ aletria/article/view/1489/1584 [30-04-2018]).

SERRANO BAIXAULI, R. (2015). Una escritura comprometida con su tiempo. El teatro de José Ramón Fernández (1992-2012). Tesis doctoral defendida en Universitat de Valencia. Disponible en línea: roderic.uv.es/handle/10550/50526 [10/07/2018].

TORRES, R.(2011). “JoséRamón Fernández, Premio NacionaldeLiteratura Dramática 2011”. El País, 10 de noviembre (también en https:// elpais.com/cultura/2011/11/10/actualidad/1320879603_850215. html [30/04/2018]).

VICENTE, C. de (2016). "El teatro en la realidad. Once notas sobre el teatro documento". Revista ArtEscena 2, 34-45 (también en http:// www.artescena.cl/el-teatro-en-la-realidad-once-notas-sobre-elteatro-documento/ [30-04-2018]).

WILMER, C.A, (2010). “La escenografía de Curt Allen Wilmer”. Cuaderno Pedagógico 49, 37-39. Disponible en línea: http://cdn.mcu.es/wpcontent/uploads/2012/08/49-LA-COLMENA-CIENTIFICA-O-ELCAFE-DE-NEGRIN-10-11.pdf [30-04-2018].

Recibido el 2 de mayo de 2018.

Aceptado el 23 de julio de 2018. 
